\title{
TERRAMYCIN IN TRACHOMA
}

\author{
BY \\ GJORGJE PAVKOVIĆ-BUGARSKI AND MILICA CVETOJEVIĆ \\ From the Regional Eye Hospital and Anti-Trachoma Centre of Vojvodina, Panceva, Institute \\ of Pathology of the Faculty of Medicine, Belgrade
}

TERRAMYCIN, which was discovered by Finlay and his collaborators (1950), was isolated from Streptomyces rumozus. The first experiments with it were made at the Mayo Clinic, Rochester, Minn., U.S.A., and it was found to produce an effect upon Gram-positive and Gram-negative bacteria, Rickettsiae, and viruses.

\section{Reports in the Literature}

Comparatively few papers have been published on the results achieved by treating trachoma with terramycin, but Bietti (1953), Bengisu Naci (1952), and Mitsui (1951) have published the results of their researches. The Japanese have been the most frequent users of terramycin in trachoma. Mitsui and others (1951) administered this antibiotic in seven hundred cases, 80 per cent. of which were reported to have been cured. These clinical findings were corroborated by their laboratory work. Inclusion bodies disappeared after a few days; histopathological analyses showed improvement; pannus disappeared after 6-10 days. Bengisu Naci (1952) treated ten patients with terramycin capsules, drops, and ointment, and later treated a hundred children, administering terramycin ointment five times a day. Laboratory and clinical control was introduced before and after the treatment. Bietti (1953) treated 206 eyes with terramycin, and thought that it influenced the virus. Good results with terramycin were obtained by Izzet (1951) in Turkey, and by Geraci (1951) in Italy. Rais (1950) investigated cases of pure trachoma and also cases in which trachoma was combined with conjunctivitis. Naccache (1953) treated 38 patients by oral administration and locally, without any toxic or allergic symptoms. Siniscal (1952) asserted that terramycin produced an effect only in cases of superinfection. Very good results were achieved by Town (1951) and Thygeson (1951), and moderate results by Focosi (1953), Lepri (1951), and Caterini and De Vincentiis (1951).

\section{Present Research}

Having investigated the results of treating trachoma with the sulphonamides, penicillin, and aureomycin, we decided to apply terramycin and observe its effect upon trachoma in the province of Vojvodina, Jugoslavia. 
Material.-We treated eighty patients with terramycin. Our research began on October 1,1952 . The cases were classified in four stages according to MacCallan (1936). We had seven cases in Stage I, forty in Stage II, and 33 in Stage III. 59 of the patients were under 20, eight between 20 and 30, and thirteen over 30 years of age. We chose patients who had not been treated previously, and those in whom the trachoma process was not old-established, so that most of them were in a progressive stage of the disease. Clinical observation was carried out by means of a biomicroscope or a loupe. Microbiological and histopathological examinations enabled us to see the effect produced on the trachomatous process itself. Some of the patients stayed in hospital for 2-3 months, and others were segregated in a home or boarding-school for trachomatous children, but most of the latter group were also treated in hospital for some time.

The patients were divided into two groups: one was treated locally with terramycin, and the other received sulphonamides, besides local therapy. All the cases, with few exceptions, were under our supervision even after the termination of treatment. In all the hospitalized cases, before the actual treatment was begun, a general examination was made. The conjunctival flora was examined in each case, and preparations of conjunctival scrapings were taken. These examinations were made frequently in the course of the treatment, and once a month or once in 2 months thereafter. In order to examine the influence of the drug on the pathological process, we made histopathological examinations, trying to find out whether, even a long time after treatment had been stopped, the pathological process still existed. Sections were taken from the upper palpebral conjunctiva, and, having been fixed in Zenker, were stained with haematoxylin and eosin or by Van Gieson's method. These were taken before and after treatment, and in seven cases also after an interval of 2-4 months. 140 sections were made from 54 treated eyes.

Clinical Features.-The peculiarity of trachoma in Vojvodina is the rare incidence of acute cases. A chronic, follicular, form of the disease, without discharge, is prevalent, and during the last 20 years it has been occurring in a very mild form. A developed pannus and damage to the eyelids are extremely rare in younger persons. The number of cases of pure trachoma is large. A fine diffused infiltration, a few follicles, opaque and differing in size, and still fewer papillae, are generally found in Stage I cases. The process begins in the upper tarsal conjunctiva, near to the free border of the tarsus or on the semilunar fold, where two or three follicles are usually aggregated. There is no discharge. In Stage II a diffused infiltration develops, there are often many opaque follicles, different in size and sometimes aggregated. There is some papillary hypertrophy, but no roughness. The process gradually penetrates deeper into the tarsus, covering the whole tarsal conjunctiva and the upper conjunctival fornix. There are follicles in the bulbar conjunctiva, especially in the upper part. Sometimes there are signs of an initial pannus in the limbus in the upper part with superficial infiltration $1 \mathrm{~mm}$. wide and initial superficial vascularization. Pannus is rarely developed, but if it occurs, the infiltration seldom penetrates deeply. In most of the Stage III cases some fine scarring is to be found. In a small number of cases scarring is prevalent, opaque follicles being found here and there with the infiltration and papillary hypertrophies, and the tarsus being infiltrated and thickened. In such cases pannus is developed and often involves the whole cornea, with deep penetration, and vision is very poor. 
Treatment.-In 41 cases the treatment was exclusively local. Ointment was applied six times a day. In 39 cases the patients also received sulphathiazole tablets by mouth. There was little change in the clinical appearances in the first month of treatment, except that in the Stage I cases one had an impression that the diffused infiltration had become smaller, especially under combined therapy. In the second month, besides the regular oral treatment, the antibiotic was administered locally by massage once a day. During the second, and, in more serious cases, during the third month, the diffuse infiltration gradually disappeared, and the follicles and papillary hypertrophies became smaller and then vanished. In a number of cases fine scarring remained, while in others the process was completely cured without scarring. In Stage II regression was slower, and in Stage III it was very slight, but it frequently occurred without any new scarring.

After the termination of the treatment the conjunctivae were pinkish-grey, thin, and smooth, sometimes with fine scarring on the surface, and sometimes without. In Stage II cases some follicles and papillary hypertrophies remained.

The effect on the pannus was favourable. We treated only eleven patients with pannus; the subjective irritation rapidly ceased, hyperaemia disappeared after 2-5 days, the conjunctival infiltration was resorbed within 5-10 days, and after a month the pannus was resorbed completely. After the termination of the treatment vascularization persisted on the corneal surface; this was very rare, but there was scarring in the long-standing cases.

Vision was considerably improved in all cases, and terramycin was seen to influence the true trachomatous pannus.

Of eighty patients, 37 ( $46 \cdot 25$ per cent.) were clinically cured: of seven Stage I cases, four (57 per cent.); of forty Stage II cases, 24 (60 per cent.); and of 33 Stage III cases, nine ( 27 per cent.). However, in some cases the pathological changes did not quite disappear even after 3 months' treatment. Follow-up examinations showed that there was a further regression of pathological changes, and so far no case has relapsed. Terramycin combined with sulphathiazole produces quicker and better effects than when it is administered locally only. In general, the more superficial the process the sooner it is cured.

\section{Biomicroscopical Investigation}

Before treatment the conjunctival surface in Stage I cases is uneven, diffused, opaque, and opalescent. Longitudinal blood vessels and the tarsus are transparent. The papillae, with a characteristic perpendicular vascularization, in the form of a bouquet, are a little increased and infiltrated, and less transparent, and form groups, causing the uneveness of the conjunctival surface. The papillary hypertrophy is greater near the conjunctival fornix. Here and there small follicles can be seen; they are whitish-grey, transparent, and not vascularized at first, but later fine capillaries can be seen on the surface. This state is directly followed by cicatrization, and fine scarring is formed, but in some cases follicles disappear without any residual scarring.

In Stage II the opalescence is greater. Some longitudinal blood vessels can be seen dimly; there are many papillary hypertrophies, the bouquet of blood vessels is very developed, and infiltration is greater. Among the papillae are seen whitish-grey follicles, hemi-ampullar in form and non- 
transparent, their surface covered with a loose net of blood vessels. Most of them are near the canthi and in the conjunctival fornix. Sometimes there is an enormous number of follicles, so that the conjunctiva has a gelatinous look. During treatment the follicles diminish gradually, become clear and white, lose their hemi-ampullar appearance, become transparent and vanish. Fine scarring is formed, and whitish lines can be seen. The papillae become flat and disappear gradually. In the cases considered as clinically cured, the conjunctiva is light, with a smooth surface, transparent, vascularization is parallel to the surface, and there are newly-formed vessels in front of and behind the fine surface scarring.

In the majority of our Stage III cases cicatrization was initial, so that biomicroscopically there was no significant difference between them and the Stage II cases. In a smaller number of cases the conjunctiva was covered with a net of fine linear scarring, sometimes forming islets with a smooth surface. Generally, blood vessels are no longer perpendicular, but parallel to the surface, behind the scars. The papillae are flat and smaller in size. The inner blood vessels can be seen. There is a fine greyish, diffused infiltration. A small number of regressing follicles can be found on the tarsal conjunctiva, especially laterally and in the conjunctival fornix. New blood vessels develop from the inner or conjunctival fornix vessels, forming a dense, superficial net. Regression and cicatrization progress during treatment. In the bulbar conjunctiva, hyperaemia and infiltration are continued into a more or less developed pannus. As for the pannus, the limbus area is infiltrated, the papillae are small, and blood vessels form a bouquet. The direct branches of the foremost conjunctival vessels penetrate into the infiltration, by which they are covered. In the distal part of the limbus can be seen round follicles, surrounded by fine blood vessels. Some of their branches cover the surface of the follicles, and there are many maculae and papillae. During treatment the infiltration is resorbed, and instead of the follicles, fine pits are formed. Vascularization is persistent.

\section{Microbiological Investigation}

In all the cases before treatment, often during the treatment, and at intervals after discontinuing treatment, the conjunctival flora was examined and preparations stained by the method of Lindner (1927) and Poleff (1951) were made from the conjunctival scrapings. Before treatment we found inclusion bodies in five of the seven Stage I cases, in thirty of the forty Stage II cases, and in eight of the 33 Stage III cases. We thus found them in 43 out of eighty cases ( 54 per cent.). After treatment we found them only in two Stage I cases, four Stage II cases, and one Stage III case. During the followup period, 2-4 months after the termination of the treatment, they were not found at all. The conjunctival flora became sterile within 2-3 days after the treatment was started. There had been many epithelial cells, which in the course of the treatment and after its discontinuance became gelatinously 
degenerate; their nucleus could not be stained and they disappeared gradually. We found Prowazek-Halberstädter bodies, initial and elementary, in the epithelial cells. Pastille and rickettsoid bodies, Leber's cells, small lymphocytes, and erythrocytes were also found.

Since the trachoma bodies disappeared in almost all cases, this could be taken as a proof that terramycin destroyed the virus. However, the fact that the inclusion bodies were found in 54 per cent. of the cases suggests that the virus may exist in an invisible form.

\section{Histopathological Investigation}

Histopathological analyses of sections taken before treatment from patients with progressive trachoma (Stages I and II) show papillary excrescences lined with epithelium on the conjunctival surface. In the subepithelial tissue, which is the basis of these formations, and also in the submucosa, there is some infiltration of lymphocytes and plasma cells, usually diffused and more or less intensive. This infiltration includes separate follicles or their conglomerates, composed of bigger or smaller lymphoid elements. Considerable hyperaemia can be seen in the same tissue. The more advanced cases show proliferation of conjunctival elements, occurring either around small blood vessels or in the follicles themselves, with here and there subepithelial cysts. In some cases there is also infiltration among the acini of the lacrimal gland.

After therapy, in a number of cases, especially those in the initial stage, a complete or partial resorption of infiltration occurs (Figs 1-6).

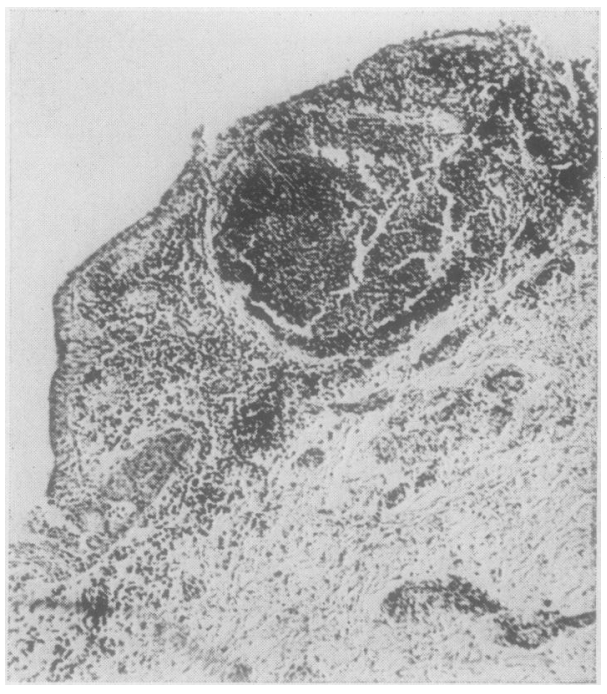

Fig. 1.-Case 18, biopsy before treatment. In the subepithelial tissue of the conjunctiva, beside a diffuse infiltration of lymphocytes and plasma cells, is a large follicle showing signs of necrosis in the middle; above it, the epithelium of the conjunctiva is partly thinned and partly missing.

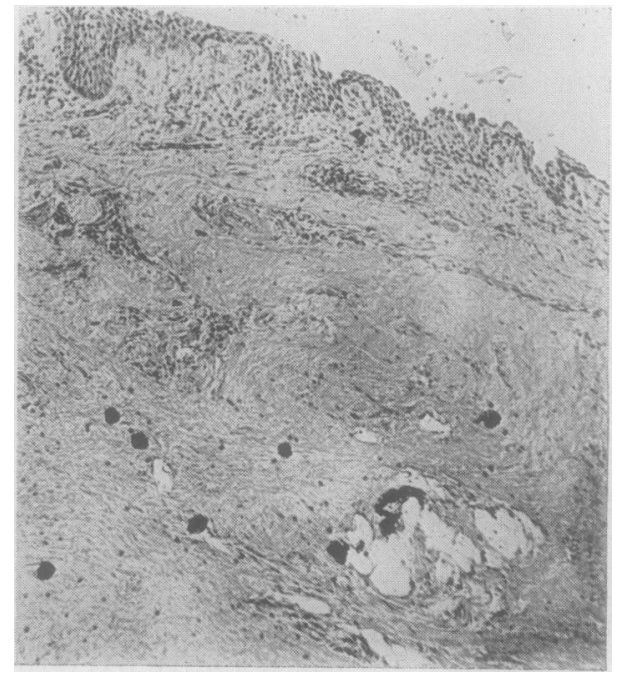

FIG. 2.-Case 18, biopsy after treatment (after 89 days). The epithelium of the conjunctiva is stratified, lining the low papillae. Subepithelial and pretarsal tissues are compact; separate lymphocytes can be seen. A fat infiltration can be seen in the pretarsal tissue. 


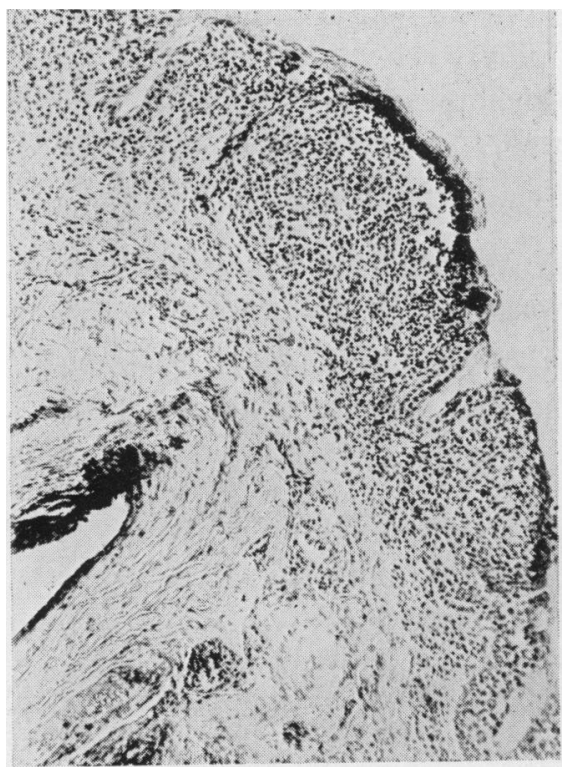

FIG. 3.-Case 2 before treatment. Papillary growth with infiltration of lymphocytes, plasma cells, and follicles.

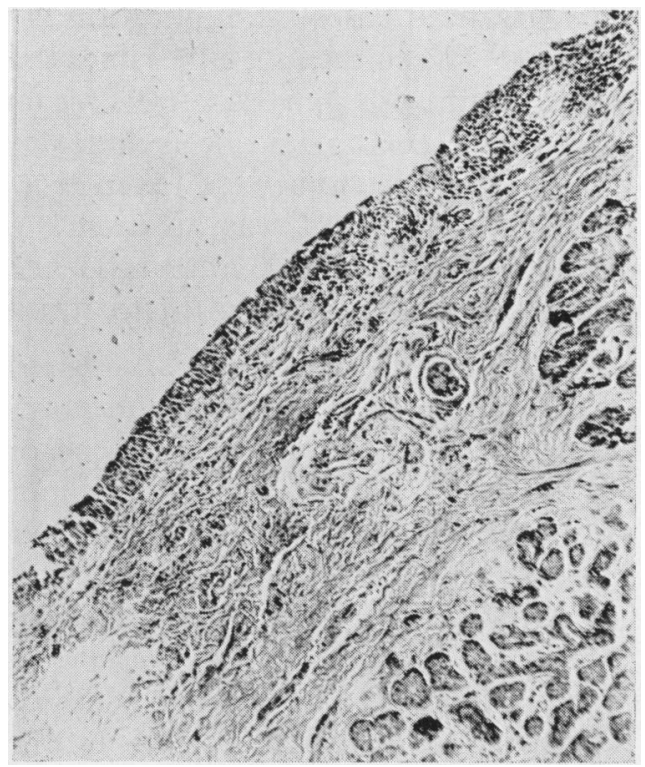

FIG. 4.-Case 2 after treatment (after 62 days). Epithelium stratified; in the subepithelial tissue rare separate lymphocytes can be seen, the tissue itself being compact.

Fig. 5.-Case 4 before treatment. In the subepithelial tissue of the conjunctiva there are follicles, on the periphery around them the beginning of a proliferation of the conjunctival elements can be seen. Under the follicles there are rather widened blood vessels.
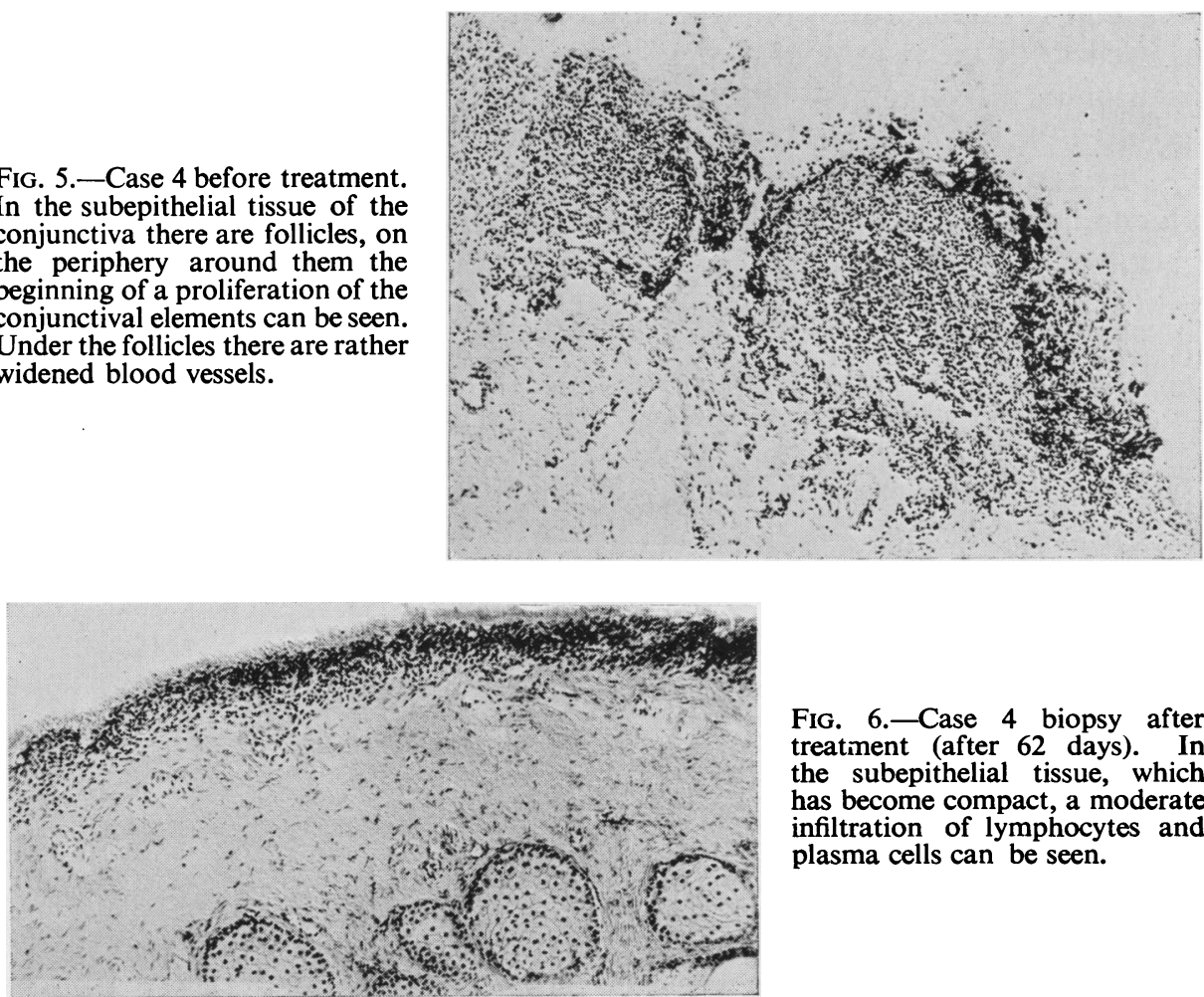

FIG. 6.-Case 4 biopsy after treatment (after 62 days). In the subepithelial tissue, which has become compact, a moderate infiltration of lymphocytes and plasma cells can be seen. 
In advanced cases the infiltration is partly resorbed and there is moderate scarring. The epithelium either lines the papillary growth or penetrates deeper into the subepithelial tissue. It becomes metaplastic and stratified. Many cases which seem to have been clinically cured, show only slight improvement. In some cases sections were taken at a longer interval after treatment, when further improvement was apparent.

There is only a moderate influence on the diffuse infiltration and the follicles, probably because the treatment was administered without massage.

\section{Summary}

Terramycin used locally favourably influences the trachomatous process, especially when combined with the oral administration of sulphonamides. Its influence on the trachomatous process is more efficacious in new cases when the tissues have not been deeply penetrated. In an advanced case at least 2 or 3 months of treatment are required.

Terramycin has a favourable effect on the pannus.

Of eighty patients, $37(46.25$ per cent.) were clinically cured, and the remaining 43 (53.75 per cent.) improved. In 39 cases, besides the local therapy, sulphonamides were given orally.

The microbiological examination indicates that the trachoma bodies disappeared during treatment in almost all cases. The histopathological examination proves that in nineteen out of 34 patients, from whom biopsies were taken after the termination of the treatment, an improvement was seen, and that in fifteen other cases the result was almost as good. A longer time is needed for the pathological signs to regress, but the fact that the regression is usually accompanied by some fine and slight cicatrization, proves the positive effect of terramycin.

Our research does not indicate that terramycin has a specific effect on trachoma, but combined with sulphonamides and aureomycin, it is a useful medicament.

\section{REFEREN}

BIETTI, G. B. (1953). Ibid., 39, 51.

BirCH-HirsCHFELD, A. (1938). "Zur pathologischen Anatomie und Therapie des Trachoma nach histologischer Untersuchung des Tarsus und seiner Bindehaut", Abh. Augenheilk., No. 27.

Caterini, G., and De Vincentis, U. (1951). Riv. ital. Tracoma, 3, 107.

Finlay, A. C., Hobby, G. L., P'an, S. Y., Regna, P. P., Routien, J. B., Seeley, D. B., Shull, G. M., Sobin, B. A., Solomons, I. A., Vinson, J. W., Kane J. H. (1950). Science, III, 85.

Focosi, U. (1953). Rev. int. Trachome, 30, 75.

Geraci, P. (1951). Policlinico Sez. prat., 58, 140.

HERRENSCHWAND F. VON (1927). "Die pathogenen Mikroorganismen des Auges". Urban and Schwarzenberg, Berlin.

IzZET, B. (1951). Göz. Klin. (Istanbul), No. 6.

LEPRI, G. (1951). Rass. ital. Ottal., 20, 15.

LINDNER, K. (1927). See Herrenschwand (1927).

MACCALlan, A. F. (1936). "Trachoma". Butterworth, London.

Mirsui, Y.(1951). World Health Organisation, Tech. Rep. Ser., No. 59. “Trachoma ”, pp. 2, 9, $14,16$.

and TANAKa, C. (1951). Antibiot. and Chemother., 1, 146; Abs. in Ophthal. Lit. (Lond.)., 5, p. 186 , No. 586 . 235.

NACCACHE, R. (1953). British Journal of Ophthalmology, 37, 106.

NataF, R. (1952). "Le trachome". Masson, Paris.

Poleff, L. (1951). Maroc. méd., 30, 107; Amer. J. Ophthal., 35, 627.

RAïs, H. (1950). Rev. int. Trachome, 27, 140.

SinisCal, A. A. (1952). Amer. J. Ophthal., 35, 671.

Thygeson, P. (1951 bid., 34, 11 .

Town. A. E. (1951 bid, 34. 723. 